Mestrando em Letras do Programa de PósGraduação em Letras da Universidade de Passo Fundo (UPF), na linha de pesquisa Produção e Recepção do Texto Literário. É bolsista da instituição e participa do projeto Mundo da leitura. Professor concursado do Estado do Rio Grande do Sul e do município de

ittps://orcid.org/0000-0002-9809-1320

E-mail: airton pott@yahoo.com.br

Recebido em: 14/2/2019.

Aprovado em: $12 / 6 / 2019$.

BR 285, São José, Passo Fundo/RS, CEP: 99052-900.

\section{Rememoração da ditadura por meio da fotografia: possíveis representações e leituras de P14311}

\author{
Photographic dictator replacement: possible representations and readings of p14311
}

Airton Pott ${ }^{1}$

Universidade de Passo, Programa de Pós-Graduação em Letras, Passo Fundo, RS, Brasil.

\section{RESUMO}

A representação e a rememoração de identidades culturais podem ser realizadas de diversas e diferentes formas: escrita histórica, ficcional, teatro, documentários, cinematografia, pinturas, imagens e fotografias. À vista disso, pretendemos analisar algumas fotografias do livro P14311, de Diego Di Niglio, o qual é relacionado ao período da ditadura militar brasileira. Além do mais, no final do livro há um texto de José Afonso Jr, professor e pesquisador de fotografia da Universidade Federal de Pernambuco (UFPE), em que ele explana algumas noções sobre o livro P14311, a câmera e a fotografia. Diante disso, nossos estudos são fundamentados em um levantamento bibliográfico a partir de conceitos sobre a fotografia, sobretudo, como forma de memória, fundamentados em Barthes (1984), Kossoy (2001), Dubois (1993) e Felizardo e Samain (2007), e também visitamos a fotografia como sendo uma forma discursiva e um lugar de fala, sendo que para isso nos reportamos aos estudos de Foucault (2008), Deleuze (1999) Ribeiro (2017) e Amaral (2005). Enfim, as linhas teóricas que escolhemos e delineamos conforme nossa proposta de investigação nos levam a inúmeras conclusões, dentre as quais destacamos que em P14311 há muita vida por trás da morte, do sofrimento e das separações de famílias nele representadas.

Palavras-chave: Ditadura. Rememoração. Livro. Fotografia(s). P14311.

\section{ABSTRACT}

The representation and recollection of cultural identities can be realized in several different forms: historical writing, fiction, theater, documentaries, cinematography, paintings, images, and photographs. In view of this, we intend to analyze some photographs of Diego Di Nigli's book P14311, which is related to the period of the Brazilian dictatorship. Moreover, at the end of the book, there is a text by José Afonso Jr, teacher and researcher of photography at the Universidade Federal de Pernambuco (UFPE), in which he explains about book P14311 camera, and photography. In this way, our studies are based on bibliographical research based on concepts about photography, mainly as a form of memory, based on Barthes (1984), Kossoy (2001), Dubois (1993) and Felizardo and Samain (2007). We visit photography as a discursive form and a place of speech, and for this, we refer to the studies of Foucault (2008), Deleuze (1999) Ribeiro (2017) and Amaral (2005). Finally, the theoretical lines that we choose and outline according to our research proposal lead us to countless conclusions, among which we emphasize that in P14311 there is a lot of life behind death, suffering and the separations of families represented in it.

Keywords: Dictatorship. Remembrance. Book. Photography(s). P14311. 


\section{Introdução}

$\mathrm{M}$ otivados em aprofundarmos um estudo a respeito da relação entre fotografia e memória, selecionamos algumas fotografias do livro P14311, do fotógrafo Diego Di Niglio. Mesmo sendo de origem italiana, Di Niglio já mora há alguns anos em Olinda, Pernambuco, onde desenvolve(u) projetos voltados à fotografia e diferentes temas sociais e culturais, dentre os quais destacamos o relacionado à ditadura, período histórico representado no nosso corpus de análise.

Das fotografias encontradas no livro P14311, selecionamos as sete que mais nos impactaram e que tinham relação com o tema que escolhemos - o da solidão e do rompimento de famílias como consequências da ditadura. Para realizarmos tais estudos, nos amparamos em dois capítulos teóricos com ênfases diferentes, mas ambos bastante pertinentes para aprofundarmos nossas percepções e pretensões.

No primeiro capítulo teórico colocamos em pauta considerações sobre a fotografia e as técnicas fotográficas, mas direcionadas à percepção e aos registros fotográficos voltados às intenções e aos atos de fotografar para arquivar e rememorar acontecimentos do passado. Para tanto, invocamos Barthes (1984), Kossoy (2001), Dubois (1993) e Felizardo e Samain (2007).

Já no segundo capítulo, direcionamo-nos à fotografia como um lugar de fala e rememoração de acontecimentos imbricados à ditadura. Julgamos imprescindível, para isso, entender o conceito de lugar de fala e a sua relação com o discurso, cujo arrolamento teórico é embasado em Foucault (2008), Deleuze (1999), Ribeiro (2017) e Amaral (2005).

Enfim, almejamos, a partir desses estudos teóricos e das delimitações temáticas, contribuir para os estudos da fotografia, da literatura e dos demais recursos que possibilitam a rememoração da ditadura e a realização do luto de familiares dos desaparecidos e mortos durante o período traumático que foi a ditadura. Além do mais, o aparato teórico nos auxilia nas análises, tanto nas técnicas adotadas na fotografia, quanto na relação dessa com a memória, sobretudo a do passado representado no livro P14311.

\section{A memória na fotografia: além de enquadramentos e flashes}

Como pode um papel despertar emoções, lembranças, memórias, sentimentos, lágrimas? Parece-nos assustador, mas ao tratarmos da fotografia, isso é no mínimo considerável. Afinal, “o que a Fotografia reproduz ao infinito só ocorreu uma vez: ela repete mecanicamente o que nunca mais poderá repetir-se existencialmente" (BARTHES, 1984, p. 13). Assim, a fotografia é, antes de mais nada, uma forma de repetição, de representação de algo por meio da captura daquilo que será transposto a uma imagem congelada e, quando olhada por alguém, causará, a esse, sensações.

Segundo Kossoy (2001, p. 36), "o homem, o tema e a técnica específica (esta, por mais avançada que seja) são em essência os componentes fundamentais de todos os processos destinados à produção de imagens de qualquer espécie". Antes de mais nada, o primeiro elemento - o homem - precisa estar disposto a fazer aquilo, estar envolvido com o tema. Só assim, consegue realizar um trabalho, mas é importante que ele tenha domínio das técnicas fotográficas, pois essas mostram o profissionalismo arraigado no processo fotográfico.

A ideia de representação por meio da fotografia já é confirmada por Barthes (1984, p. 127-128), que chama esse processo de ratificação: “a essência da Fotografia consiste em ratificar o que ela representa". Em outras palavras, a fotografia é a confirmação daquilo que nela consta. Temos, então, a fotografia como uma imagem do real:

A imagem do real retida pela fotografia (quando preservada ou reproduzida) fornece o testemunho visual e material dos fatos aos espectadores ausentes da cena. A imagem fotográfica é o que resta do acontecido, fragmento congelado de uma realidade passada (KOSSOY, 2001, p. 36-37)

Além do mais, podemos estabelecer, nessa perspectiva, uma relação entre fotografia e memória, haja vista que por meio da imagem fotográfica podem ser arquivados acontecimentos do passado. Esse arquivamento é o que vai passar conhecimentos e informações aos que não estiveram naquele lugar e momento e ativar a memória daqueles que tiveram alguma relação com o que está ali representado.

De acordo com Felizardo e Samain (2007, p. 210): "no íntimo da palavra, as duas, memória e fotografia se (con)fundem, são uníssonas, uma está contida 
na outra, estão intrinsecamente ligadas, fundamentalmente 'enamoradas'". Portanto, a fotografia guarda nela aquilo que estava também na memória das pessoas, mas também mantém o passado vivo na memória.

Diante desses fatos, podemos afirmar que fotografia e memória se "enamoram" duplamente, no ato da produção da fotografia, bem como no momento em que alguém olha aquela fotografia e lembra ou imagina algo a partir do que vê ali registrado. Enfim, socialização de fotografia e memória nos compele ao fato de que:

Aquele ou aquela que é fotografado, é o alvo, o referente, espécie de pequeno simulacro, de eídolon emitido pelo objeto, que de bom grado eu chamaria de Spectrum da Fotografia, porque essa palavra mantém, através de sua raiz, uma relação com o "espetáculo" e a ele acrescenta essa coisa um pouco terrível que há em toda fotografia: o retorno do morto (BARTHES, 1984, p. 20, grifo do autor).

0 retorno do morto pela fotografia anunciado no fragmento citado nos incita à ideia de que a fotografia é uma forma de guardar a memória. Logo, ela é uma bela recordação, mesmo que muitas vezes ela remeta às concepções de morte, saudades, passado.

Mediante esses fatos, mencionemos os três estágios que marcam a existência de fotografia, segundo Kossoy (2001): a intenção, o ato do registro que deu origem à materialização da fotografia e os caminhos percorridos por essa fotografia. A respeito desse último estágio nos é enfatizado que são

Os caminhos percorridos por essa fotografia, as vicissitudes por que passou, as mãos que a dedicaram, os olhos que a viram, as emoções que despertou, os porta-retratos que a emolduraram, os álbuns que a guardaram, os porões e sótãos que a enterraram, as mãos que a salvaram (KOSSOY, 2001, p. 45).

Diante disso, impossível não lembrarmos da ditadura ocorrida no Brasil em meados das décadas de 1960 a 1980, sobretudo ao lermos uma das partes acima referentes ao terceiro estágio da fotografia - a dos porões. Nesse período histórico, melhor tivesse sido se apenas fotografias tivessem sido enterradas nos porões. Na nossa contemporaneidade, porém, foquemos nas mãos que visam salvar ao menos a memória dos torturados, desaparecidos e enterrados nos tempos da ditadura.

Lutemos para que a memória seja mantida viva em suas formas de representação, inclusive na fotografia. Para enfatizarmos sobre isso, valemonos de Felizardo e Samain (2007, p. 211): "o fato de a fotografia ser uma representação do 'real' pode não ser suficiente para lhe conferir credibilidade absoluta. Assim como a memória, ela pode 'selecionar' partes do real a fim de iludir, manipular, fazer parecer". Portanto, tanto a memória como a fotografia vão guardar em si as vontades e os anseios de seus portadores, de seus donos. No entanto, para esses, elas são a veracidade, os recursos para guardar e propagar as informações com as quais seu dono se depara.

Dubois (1993, p. 170) faz sobressair a nós que "o ato fotográfico lança no mundo em cada um de seus golpes, em cada uma de suas tomadas, um véu transparente e paralisante". Logo, é transparente pelo fato de reproduzir aquilo que ele captou e capturou e paralisante pelo fato do capturado ficar estático, ser imóvel na fotografia. Diante disso, o ato fotográfico, seguindo a analogia de Dubois (1993), é um véu, sobretudo sedutor, além de transparente e paralisante. A fotografia e o seu ato é o véu da dança do ventre do mundo fotográfico, e o fotógrafo é seu condutor.

Perante essas circunstâncias, lembremos que é impossível para um fotógrafo capturar tudo em sua fotografia. No entanto, precisamos pensar no porquê de suas escolhas terem sido voltadas para fotografar algo daquela forma, e não outro objeto ou de outro jeito. Logo, o autor põe um pouco de si e de seus gostos na foto. Além do mais, aquilo que está na foto, motiva muitas vezes a pensar o além daquilo que está ali, o que pode ser proposital, uma estratégia para deixar a foto mais bonita, para causar impacto, ou então para instigar os outros a imaginarem o que está ali e por trás dela.

Destarte, compreendamos a fotografia como uma forma de testemunho, sendo que "o testemunho que é o registro fotográfico do dado exterior é obtido/elaborado segundo a mediação criativa do fotógrafo" (KOSSOY, 2001, p. 50). Sendo assim, muito do sucesso e da aceitação da fotografia pelos outros se deve à criatividade do fotógrafo quando faz a foto, fazendo a seleção de como aquela imagem fica mais bonita, mais representativa.

Ademais, a sua beleza, as lembranças proporcionadas e ali guardadas não nos deixam esquecer que a fotografia "suscita e ressuscita sentimentos" 
(FELIZARDO; SAMAIN, 2007, p. 214). Em outras palavras, a fotografia instiga a memória, a qual vai despertar lembranças, emoções, recordações. Enfim, faz reviver mentalmente aqueles momentos ali registrados na fotografia. Somos, assim, convidados a visitar dois grandes tipos de concepção fundamentados por Dubois (1993, p. 45, grifo do autor):

A foto como espelho do mundo e a foto como operação de codificação das aparências - tem como denominador comum a consideração da imagem fotográfica como portadora de um valor absoluto, ou pelo menos geral, seja por semelhança, seja por convenção.

Dado o exposto, a foto como espelho nos incita ao fato de que ela é o reflexo de algo, de uma realidade, e ela como operadora de codificação de aparências mostra que aquela realidade foi capturada e transformada em sua representatividade, no caso a fotografia. Desse modo, a fotografia é portadora de significados, valores, cultura, sendo que esses significados são também reportados ao receptor da fotografia.

De acordo com Barthes (1984, p. 39, grifo do autor): “como Spectator, eu só me interessava pela Fotografia por 'sentimento'; eu queria aprofundá-la, não como uma questão (um tema), mas como uma ferida: vejo, sinto, portanto, noto, olho e penso". Além disso, essa percepção da ferida por trás da fotografia prefigura-se a nós de fora bastante interessante, haja vista que algo motiva o fotógrafo a querer fotografar aquilo, e uma ferida é aquilo que deixa marcas em seus pensamentos, em seu coração. A fotografia já feita pode despertar a ferida da saudade, mas a fotografia sendo feita, naquele momento, pode ser uma forma de registrar aquilo que lhe causou notoriedade, comoção, identificação, marcas.

Em vista à explanação feita, concluímos que "toda fotografia representa o testemunho de uma criação. Por outro lado, ela representará sempre a criação de um testemunho" (KOSSOY, 2001, p. 50). Portanto, enquanto arquiva em si algo, a fotografia passa a ser uma criação e ela mesma é testemunha daquilo que ela possibilitou. Além disso, ela é um testemunho, pois participou da criação de algo que comprova a existência daquilo que ela mesma representa. Enfim, a fotografia resgata o passado e mantém vivo o morto.

\section{0 "lugar de fala" da fotografia no processo de rememoração da ditadura}

"Quem fala?" (FOUCAULT, 2008, p. 5.), uma indagação curta, que nos transparece inclusive certa banalidade, mas diante de determinados contextos possui uma grande significação e pode nos surpreender com os fatos aos quais ela leva. Esclarecemos algumas possibilidades ao longo de nossa explanação.

Ao adoecermos, por que procuramos um médico? Ao querermos construir, por que procuramos um engenheiro civil? Ao precisarmos de alguém que concerte nosso carro, por que procuramos um mecânico? Simples, porque eles são os profissionais que têm conhecimento sobre essas nossas necessidades. Logo, cada um têm a sua posição social, bem como o seu "lugar de fala". Um profissional sem a sua roupa de trabalho, o seu crachá ou demais "denúncias" de sua profissão, dificilmente será identificado fora do seu ambiente de trabalho como sendo daquela profissão. Ou seja, a sua relação social será como a de qualquer outro, pelo menos é o que soa a nós como apropriado.

"Por que eu escrevo? / Por que tenho que / Porque minha voz / em todas suas dialéticas / foi silenciada por muito tempo" são palavras de Jacob Sam-La Rose ([2017] apud RIBEIRO, 2017, p. 55) citadas por Djamila no início de um dos capítulos de $O$ que é lugar de fala. Ela remete a muito, mas principalmente àquilo que vai além das margens dos favorecidos, do padronizado, do canonizado. Dessa forma, as vozes silenciadas podem ser das vítimas das ditaduras (ou familiares delas), de homossexuais, de negros, de mulheres, de grupos religiosos, de ateus, dentre outros grupos que despertam em outrem a manifestação do diferente do convencional, do tradicional.

Logo, propõe que é necessário considerar tal contexto para entender o que é lugar de fala, cujo conceito deve ser pensado a partir do que é "discurso". De acordo com Foucault (2008, p. 55, grifo do autor): "certamente os discursos são feitos de signos; mas o que fazem é mais que utilizar esses signos para designar coisas. É esse mais que os torna irredutíveis à língua e ao ato da fala.".

Dessa forma, o discurso por trás de um texto, de uma palavra, de uma imagem, é dotado de significação. Afinal, por trás da língua e do ato de falar há uma gama do "a mais" do que parece, à primeira vista, estar ali, muita há que passa por despercebido ou até mesmo é desconhecido a inúmeras pessoas, 
ainda mais ao tratarmos de um período histórico onde houve ocultamento de inúmeros fatos ocorridos, como é o caso da ditadura militar.

Incitada no conceito foucaultiano de "discurso", Ribeiro vai corroborar que ele é compreendido "como um sistema que estrutura determinado imaginário social, pois estaremos falando de poder e controle" (RIBEIRO, 2017, p. 56). Na sequência, exemplifica essa asseveração a partir de ocorrências, inclusive na internet, em que pessoas comentam que aquele lugar e espaço não é o apropriado para fazer determinados comentários, e ou diferentes formas de manifestações de opiniões.

Dado o exposto, podemos acrescentar que os pensamentos, as ações, os costumes e as pessoas são mutáveis, assim como mudam os discursos dessas, por busca, vontade ou instinto próprios, por influência de outros, enfim, inúmeras circunstâncias que contribuem para que ocorra mudança. Muitas vezes, para haver esse processo mutatório, é preciso que haja uma nova criação. Para tanto, "no limite de todas as tentativas de criação, existem espaços-tempos. É só isso que existe” (DELEUZE, 1999, p. 5).

Em linhas gerais, pensemos no espaço-tempo como condições para criar, ou seja, quando alguém cria algo, ele cria em um determinado espaço e precisa de um tempo para fazer essa criação. É esse espaço-tempo que permite ele se expressar, se manifestar. Logo, a sua criação é influenciada pelo seu espaço, seja esse físico, social ou moral e tende a manifestar esse lugar de fala, de expressão. Além do mais, "uma fala não pode ser analisada de forma deslocada das condições sociais de seu falante" (AMARAL, 2005, p. 108).

Sendo assim, um autor tem muito a enunciar por meio de seu texto, um cineasta, pelo seu filme; um cantor, pela sua música; e um fotógrafo, pela sua fotografia. Dessa maneira, a criação é a forma que o seu criador encontrou de expressar suas ideias, suas emoções, suas percepções e seu conhecimento, por meio de uma forma e em um determinado lugar.

A respeito do lugar ocupado na sociedade, Ribeiro (2017, p. 69) afirma que "o lugar social não determina uma consciência discursiva sobre esse lugar. Porém o lugar que ocupamos socialmente nos faz ter experiências distintas e outras perspectivas". Logo, independentemente de seu posicionamento, de seu discurso, o sujeito tem as suas experiências determinadas ou influenciadas mediante a sua colocação diante das relações de poder, ou seja, isso é consequência da limitação causada pelo contexto em que está inserido.
Além do mais, determinados discursos existentes na nossa contemporaneidade jamais poderiam existir na época aos quais se referem, o que já era ratificado por Foucault (2008, p. 50): "não se pode falar de qualquer coisa em qualquer época". Isso também equivale à fotografia. As fotografias do livro de Di Niglio, por exemplo, algumas das quais apresentaremos e analisaremos no próximo capítulo, seriam censuradas no período que elas rememoram. Logo, a expressão é, de certa forma, sempre controlada por inúmeros fatores, ou seja, para poder enunciar, para poder ter um lugar de fala, é preciso espaço mediante outros lugares e outros "falantes".

Sendo assim, um discurso novo não surge do nada, e nem está desvinculado de todo o restante. Logo, esse novo discurso está vinculado a outros discursos, sejam eles semelhantes e sob os mesmos pontos de vista ou não, instituindo uma relação (inter)discursiva. Por exemplo, a representação da ditadura por meio da fotografia, que é uma das nossas motivações de investigação e análise dos nossos estudos, é uma forma diferente de manifestar a prática discursiva. Logo, cada fotografia, assim como cada texto, possui as suas próprias características discursivas e enunciativas. Pensemos as fotografias como ato de resistência:

A obra de arte não é um instrumento de comunicação. A obra de arte não tem nada a ver com a comunicação. A obra de arte não contém, estritamente, a mínima informação. Em compensação, existe uma afinidade fundamental entre a obra de arte e o ato de resistência. Isto sim. Ela tem algo a ver com a informação e a comunicação a título de ato de resistência (DELEUZE, 1999, p. 13).

Nessa perspectiva, as fotografias sobre o período da ditadura voltamse também para um ato de resistência, elas nos informam e comunicam sobre acontecimentos relacionados às vítimas da ditadura, aos episódios que aconteciam naqueles anos. Como Deleuze (1999) acentua no fragmento transcrito anteriormente, a obra de arte não é um instrumento de comunicação.

Pensemos, então, que, ao olharmos para os álbuns de família, normalmente vemos ali também fotos com entes queridos que já deixaram a vida terrena, mas são lembrados por nós, sendo que tais lembranças são possibilitadas ou facilitadas graças às fotografias. Algo semelhante ocorre com fotografias sobre episódios relacionados aos acontecimentos no período da ditadura, ajudam a 
manter viva a memória das vítimas mortas. Logo, a fotografia é um lugar de fala, por meio de cores e formas, que pode representar outros inúmeros lugares de fala.

Dessa forma, a fotografia pode ser considerada um documento, um lugar onde são guardadas informações, lembranças. Afinal, "o documento sempre era tratado como a linguagem de uma voz agora reduzida ao silêncio: seu rastro frágil, mas, por sorte, decifrável" (FOUCAULT, 2008, p. 7). Logo, a fotografia, percebida como um documento, é uma possibilitação de voz, de manifesto de lugar de fala do passado revivido no presente. Logo, existem acontecimentos do passado decifráveis graças também aos registros fotográficos.

Diante dessas circunstâncias, somos convidados a concordar com Deleuze (1999, p. 13) quando afirma que "a arte é aquilo que resiste, mesmo que não seja a única coisa que resiste". Desse modo, pensar a arte como forma de resistência permite inferir que a arte, bem como outras formas de expressão e manifestação, são formas de resistência, inclusive para dar visibilidade para o seu eu e a sua criação, para que os outros olhem e percebam a sua criação, o seu entorno social também, ou seja, o seu lugar de fala.

Portanto, ressaltamos, a partir das argumentações feitas, que existe verbalização da vontade de dar voz às diferentes vozes... Discursos aos diferentes discursos. Vozes aos donos das vozes... Aqueles que vivenciaram o discurso da repressão, da exclusão, da tortura, das injúrias, do lado desumano do ser humano. Além do mais, a fotografia de Di Niglio (2018) rememora, em imagens, por meio de diversos tamanhos, proporções, formas, cores, ângulos e flashs, muitas vozes, muitos discursos e muitos episódios ocorridos no tempo da ditadura, o que nos auxiliou na escolha de seu livro P14311 para nossos estudos também analíticos aqui propostos e fundamentados.

\section{Apresentação e considerações sobre o livro P14311}

P14311 pode remeter para alguns de nós a um código, a uma placa ou também a uma pessoa vestida com roupas listradas em preto e branco segurando algo que contém algarismos. Como já havíamos evidenciado no capítulo anterior, por se tratar de um livro com registros fotográficos sobre a ditadura, fiquemos com a última das opções, já que ditadura também lembra prisão.
Diego Di Niglio, o autor do livro P14311, é alguém que se declara apaixonado por fotos. Artista e fotógrafo contemporâneo, Di Niglio nasceu em 1975, sendo que o seu berço de nascimento foi Milão, Itália. Ele já realizou diversas exposições fotográficas e participa de vários projetos fotográficos, sendo que um deles é, inclusive, voltado para a nossa temática aqui selecionada. Tal projeto é intitulado "Marcas da memória: história oral da anistia no Brasil aos 50 anos do golpe militar de 1964".

Percebemos, através de suas fotos, que Di Niglio se preocupa com as questões sociais, históricas e culturais. Em seu livro P14311, há uma série de fotografias que podem ser relacionadas, de uma ou outra forma, à ditadura. No entanto, como sabemos, esse foi um período histórico de muitos acontecimentos, o que nos leva a presumir que cada fotografia sua remete a algum aspecto diferente da ditadura. Diante disso, como são dezenas de fotos no livro, selecionamos aquelas que mais se voltassem para a concepção do rompimento e sofrimento familiar causados pelo desaparecimento de vítimas da ditadura, aquelas que tentaram ocultar e fazer com que todos esquecessem.

Comecemos, porém, nossas análises e considerações sobre o livro a partir das últimas páginas da obra, nas quais encontramos textos de José Afonso Jr., professor e pesquisador de fotografia da Universidade Federal de Pernambuco (UFPE). A sua escrita é voltada para as duas temáticas centrais do livro P14311 - fotografia e ditadura. Afonso Jr. apresenta-nos, por meio de suas palavras, aquilo que imaginamos sobre a ditadura a partir das fotos do livro, relacionadas às técnicas da fotografia. Ele nos convida a revisitarmos às emoções e aos sentimentos já despertados pelas fotografias já a partir do título sobre as suas considerações - "Imagens ausentes, imagens que faltam".

Como já evidenciamos anteriormente, nossas considerações partem do final do livro devido à disposição das fotografias e ao delineamento que fizemos a partir dele para nossos estudos aqui propostos. Sendo assim, reproduzimos abaixo a última fotografia do livro: 
Figura 1 - Reprodução da última fotografia do livro (Fotografia 1)

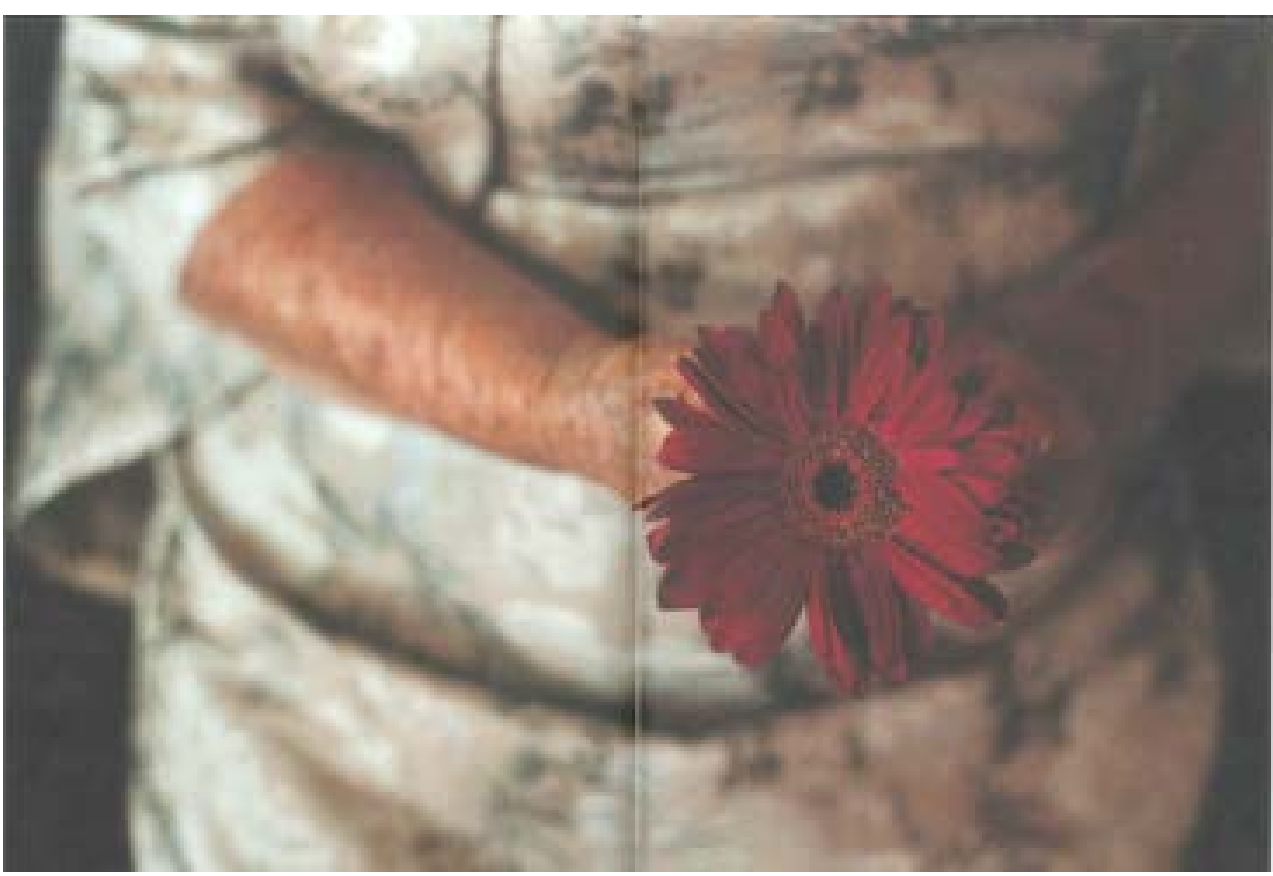

Fonte: DI NIGLIO, $2018^{2}$

Inúmeras fotografias despertaram em nós vários sentimentos, identificações e comoções, mas especialmente essa, representada acima, nos possibilitou também lembranças próprias - recordações de nossos avós, com suas purezas e singelezas, o que também nos foi transmitido pela senhora da foto. 0 fato de sua face não aparecer impulsiona ainda mais essa semelhança particular e familiar para nós, receptores e admiradores da fotografia.

A flor, que é o detalhe enfatizado nessa fotografia de Di Niglio, "olha-nos" fixamente. Possivelmente, esse detalhamento e enquadramento adotados pelo fotógrafo fizeram com que o rosto e o restante do corpo da senhora não fossem revelados.
No entanto, além disso ter possibilitado recordações próprias a nós, isso também revela que o fotógrafo tem outras intenções por trás de sua opção de enfoque na flor.

Os traços fortes e vermelhos da flor dispostos em destaque sobre o restante da foto lembram-nos da imobilidade amorosa ou fúnebre, termo(s) que Barthes (1984) usou para designar a fotografia e seu referente. Ao olharmos a foto de uma senhora com uma flor vermelha na mão é impossível não pensarmos no amor do seio familiar, representado também na foto, mas ao sabermos que ela está embalsamada em contexto da ditadura, torna-se difícil não pensar no lado fúnebre que ela nos desperta. Essa senhora idosa pode ser, por exemplo, alguém que se encontra em meio à tristeza, à amargura, ao sofrimento pela perda do marido, de um filho, enfim, de um ente querido.

Além do mais, o fundo preto e apagado encontrado na foto intensifica esse lado fúnebre da foto, o que também é ocasionado pelo fato de a foto conter um lado mais claro e um lado mais escuro. 0 lado mais escuro, que, aliás, é o lado em que está a flor, nos lembra a morte, o sofrimento, o luto, o lugar de fala de alguém que está triste e amargurado. Já o outro lado, o claro, revela uma luz, que pode representar a esperança dessa senhora, ou seja, é o lugar de fala de alguém que ainda tem esperança de dias melhores ou de que seu familiar desaparecido volte.

Diego Di Niglio poderia ter optado por dispor essa foto em apenas uma página. No entanto, intencionalmente ou não, a marca encontrada no centro da foto, que, na verdade, é a separação das páginas dos livros, representa a nós, simbolicamente, também o sofrimento e a repartição de um coração sofrido. Enfim, muitas mais são as leituras possíveis dessa foto, mas o fato de ser voltada à temática da ditadura nos faz pensar no sofrimento das famílias destruídas pela ditadura.

Na página anterior a essa fotografia, deparamo-nos com uma que nos representa ser a mesma mulher da outra imagem principalmente devido à roupa e seus detalhes, haja vista que novamente o seu rosto não nos é revelado, conforme podemos perceber na transposição da foto:

Aproveitamos para evidenciar que o livro não é paginado. 
Figura 2 - Reprodução da fotografia 2

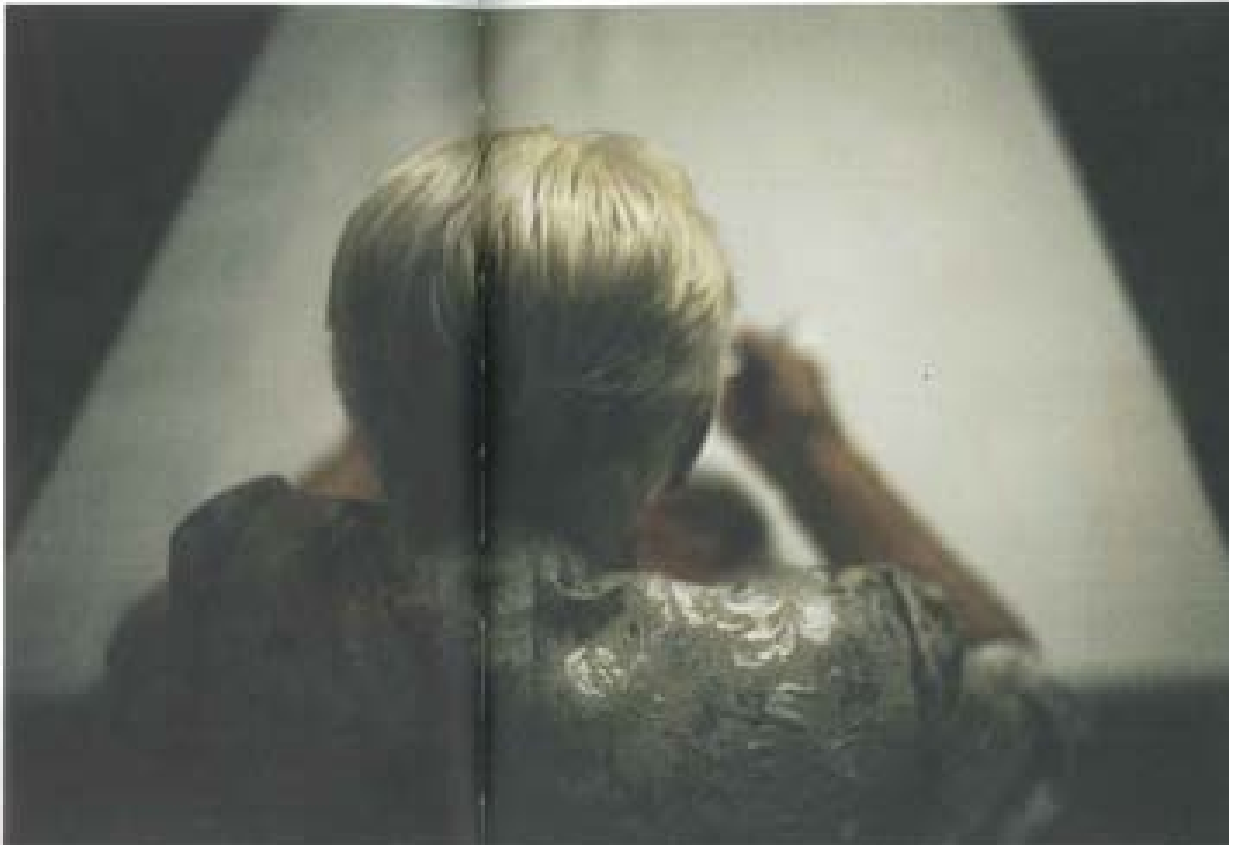

Fonte: DI NIGLIO, 2018.

No entanto, sendo ou não a mesma mulher, temos novamente uma fotografia com intenções semelhantes à outra - a ênfase da solidão e de possível momento de recordações, lembranças e memórias. A propósito, evidenciamos na seção teórica a relação entre fotografia e memória, sendo que esta é instigada pelo arquivamento e registro feitos pela outra.

A Figura 2 parece guardar literalmente em si o registro da memória. Conforme podemos perceber, parece-nos ser uma pessoa que está lembrando de algo ou fazendo algum tipo de escrita, já que aquilo que ela está segurando em sua mão direita poderia ser uma caneta, o que está na sua frente algum tipo de caderno, livro ou outro tipo de papel e o objeto branco, retangular e grande a sua frente representa-se a nós como uma mesa. No entanto, poderíamos pensar também que ela está comendo algo, se o objeto que ela segura fosse um garfo, uma faca ou algo assim e o que está disposto a sua frente fosse um prato. Enfim, a falta de nitidez nos deixa essa incerteza, que provavelmente foi intencionada por Di Niglio.

Esses detalhes ofuscados, opacos, encontrados também na Figura 1, representam justamente essa incerteza, essa imprecisão dos fatos, já que na ditadura muito ficou no oculto, no não revelado. Chama-nos a atenção também o fato de na Figura 2, assim como na outra, haver um lado mais claro e o outro mais escuro, o que novamente nos representa o obscuro dos fatos de um lado e a esperança do outro. Além do mais, o fundo preto novamente se faz presente, o que ocorre, por sinal, na maioria das fotos de Di Niglio.

Ao compararmos ainda as duas fotos analisadas, representou-nos significativo o fato de a última foto referenciada não ocupar as duas páginas inteiras do livro, como a outra foto. Ela é colocada no canto direito e inferior, sendo que acima dela, bem como para o lado esquerdo é deixado de ponta a ponta, na vertical e na horizontal, uma margem branca até as extremidades das páginas. Esse branco, em contraste com o fundo preto da fotografia novamente nos representam a ideia de luz e escuridão, de esperança e sofrimento, de esquecimento e memória, de apagamento e de registro.

Na página anterior a essa fotografia da mulher sentada inclinadamente, há novamente um jogo de efeitos entre o claro e o escuro, a sombra e a luz. No entanto, nela não há uma pessoa em si, mas sim objetos que nos levam à presença (ou ausência) de uma, conforme podemos averiguar abaixo: 
Figura 3 - Reprodução da fotografia 3

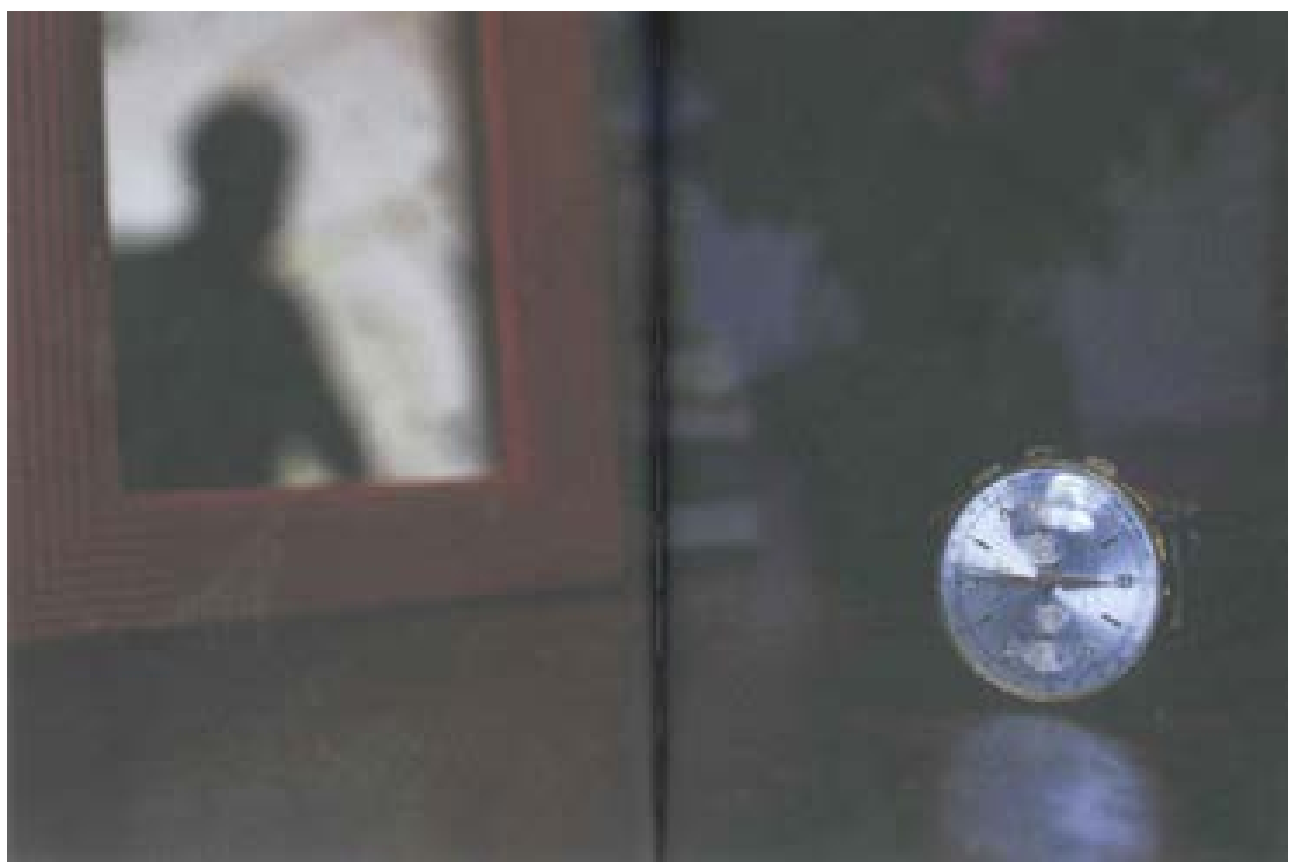

Fonte: DI NIGLIO, 2018.

Se os dois objetos dispostos na Figura 3 - o relógio e o porta-retrato possuem relação com as duas fotos que a sucedem no livro e consideramos anteriormente, não o sabemos. No entanto, relacionada ou não, podemos fazer algumas possíveis leituras sobre ela.

Mencionamos, anteriormente, que a Figura 3, assim como as outras duas, possui oscilação na luminosidade. 0 relógio de pulso, que marca seis horas, está destacado no lado direito da foto, e há certa luminosidade em cima dele, que provavelmente vem de alguma luz de outro lugar. Quanto mais perto do objeto sobre o qual está o relógio, mais escuro ele é, mas a maior claridade está para o lado esquerdo do ponteiro indicativo das horas, no número seis, e o lado direito do que indica os minutos, no número doze, ambos justamente para os lados onde os ponteiros vão conforme o tempo passa, desde que o relógio esteja funcionando devidamente.

Além do mais, a luminosidade do relógio permite que o seu reflexo apareça no objeto sobre o qual ele está colocado, ainda mais pelo fato de o entorno e os fundos de onde está o relógio estar escuro, tanto é que nem enxergamos sobre onde está o relógio. Não só simbólica, mas também literalmente esse reflexo simboliza as marcas do tempo - tanto do tempo representativo no relógio, quanto o passar do tempo na vida das pessoas, aquele que deixa saudades, lembranças, memória, que parece não passar para aquela pessoa que está esperando alguém voltar. Isso nos fez lembrar da problemática do tempo e a fixação dele na fotografia enfatizada por Dubois (1993) e a qual nos referimos na seção teórica.

De certa forma, o outro objeto que aparece na fotografia - que é um portaretrato - também representa a marca do tempo, que passa. No entanto, esse passar do tempo ali demarcado não é o das horas e dos minutos, mas sim daquele tempo que deixou o passado para trás, intensificado por uma das possíveis representações do relógio na fotografia. Esse passado que não volta mais, que deixou memórias, lembranças, saudades e, possivelmente sofrimento, é marcado sobretudo pelo fato de constar, dentro do porta-retrato, a sombra de uma pessoa, pelo menos o contorno e o formato do elemento escuro na foto nos permitem concluir que seja uma, sendo que o fundo dele é bem mais claro.

Deveras poderíamos ser questionados sobre o fato de ser apenas uma foto ou então duas, já que cada objeto aparece em uma página diferente. Porém, somos levados a pensar que seja a mesma foto, pois, mesmo sendo um fundo escuro, há partes que demarcam uma diferente tonalidade e disposição de outros elementos que nos permitem tais percepções. Por exemplo, mesmo que não seja identificado, pelo menos por nós, o que está ao lado esquerdo do porta-retrato (e à nossa direita, portanto), o jogo entre partes mais claras e mais escuras no sentido horizontal nos permitem concluir que seja a mesma foto.

Dentre outras muitas fotografias que nos chamaram à atenção, por inúmeros motivos há, em algumas páginas anteriores, duas que se enquadram perfeitamente em nosso delineamento de análise aqui proposto - o rompimento de famílias e as marcas do tempo e da memória. Cada foto está em uma página separada, mas ambas centralizadas e inclusive com o mesmo tamanho, como podemos verificar abaixo: 
Figura 4 - Reprodução da fotografia 4
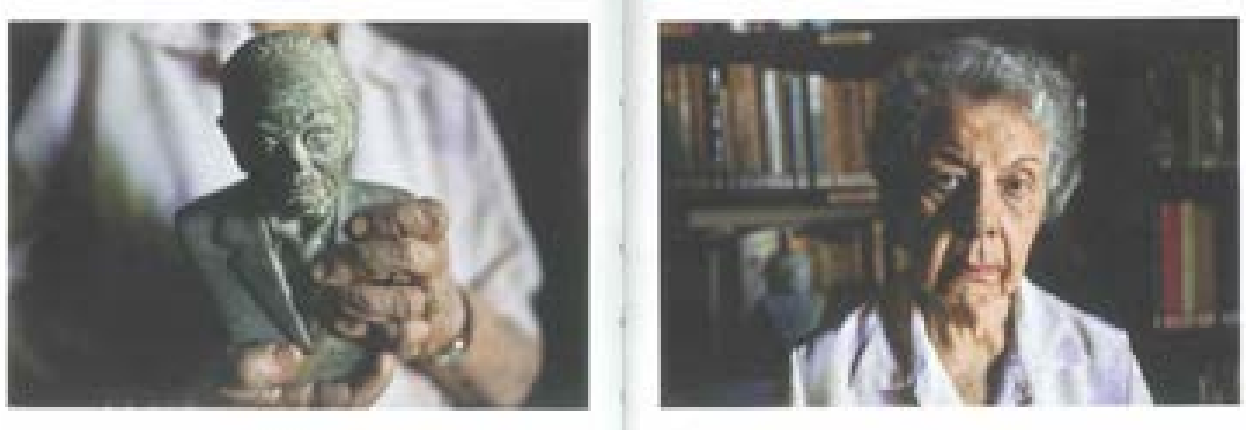

Fonte: DI NIGLIO, 2018

Na Figura 4, na foto à direita, há uma senhora que nos olha séria e fixamente. Portanto, enxergamos o rosto dela, diferentemente da outra, cuja fotografia analisamos anteriormente. Essa mulher tem as feições tristes, de alguém que está amargurado, mas olha para frente, nos olha nos olhos, talvez como forma de encarar-nos, ou então de súplica, podendo estar pedindo nossa ajuda e compaixão.

A mulher aparece centralizada na foto, em um primeiro plano, também chamado de close. Há também um jogo de luminosidade disposto entre a mulher e o fundo em que ela aparece, sendo que seu lado esquerdo está mais claro que seu lado direito, e os fundos são justamente o contrário - o fundo do lado esquerdo da mulher é escuro e do lado direito é claro.

Esse jogo de luzes reforça a nós algo semelhante à outra. 0 lado escuro, revela a tristeza e a amargura em que ela possivelmente está, um lado obscuro, fechado, introspectivo, apagado, mas no fundo há a luminosidade da lembrança, das memórias. Já o outro lado, mostra a escuridão aos fundos, que pode representar a sombra de um passado traumático, mas a luz refletida na mulher nos revela a esperança de um futuro melhor, a esperança de que essa mulher tenha dias melhores, que talvez a faça sorrir novamente.

Ao olharmos para o cenário da foto, constatamos a presença de uma estante com dezenas de livros, o que permitiria concluir que ela está numa biblioteca. Poderíamos, também, pensar que ela possui esses livros em casa, o que nos parece ser o mais provável, pois há uma estátua que aparece na fotografia em frente aos livros e sobre o ombro direito da mulher. Mesmo não estando muito nítida, a estátua que aparece aos fundos da foto à direita parece ser a mesma que está sendo segurada pela mulher na outra foto.

Além do mais, temos mais precisão aqui de que é a mesma mulher, pois as cores e os detalhes da blusa que a mulher está usando são as mesmas em ambas as fotografias. A respeito da estátua que essa senhora idosa segura firmemente em suas mãos, podemos enfatizar que é, evidentemente, de um senhor, o que nos permite inferir que seja seu marido. Enfim, como se tratam de fotografias relacionadas à ditadura ousaríamos afirmar que ele está desaparecido, o que se torna o motivo das tristes afeições da outra foto.

Sobre a tecnicidade da foto, ressaltamos que a foto da esquerda está em um plano detalhe, uma vez que o fotógrafo põe em evidência a estátua e as mãos da mulher que a seguram. 0 anel que ela usa no dedo anelar esquerdo reforça a ideia de que o homem representado na estátua é seu marido, sendo, portanto, a aliança o símbolo da união deles. Além do mais, assim como a outra foto, há uma luz mais clara na direita da foto e mais escura na esquerda, o que reforça as percepções das dualidades já salientadas nas considerações e análises sobre a outra foto.

Gostaríamos de analisar todas as fotos do livro, mas por ora nos detenhamos a apenas mais duas, que na verdade possuem o mesmo cenário, selecionadas entre muitas outras devido à presença de elementos que nos despertaram curiosidades pessoais e seguem a delimitação que estabelecemos como temática de escolha de fotografias - a saudade de um ente familiar desaparecido. Antes de fazermos a explanação das nossas percepções, dispomos abaixo as duas fotografias: 
Figura 5 - Reprodução da fotografia 5

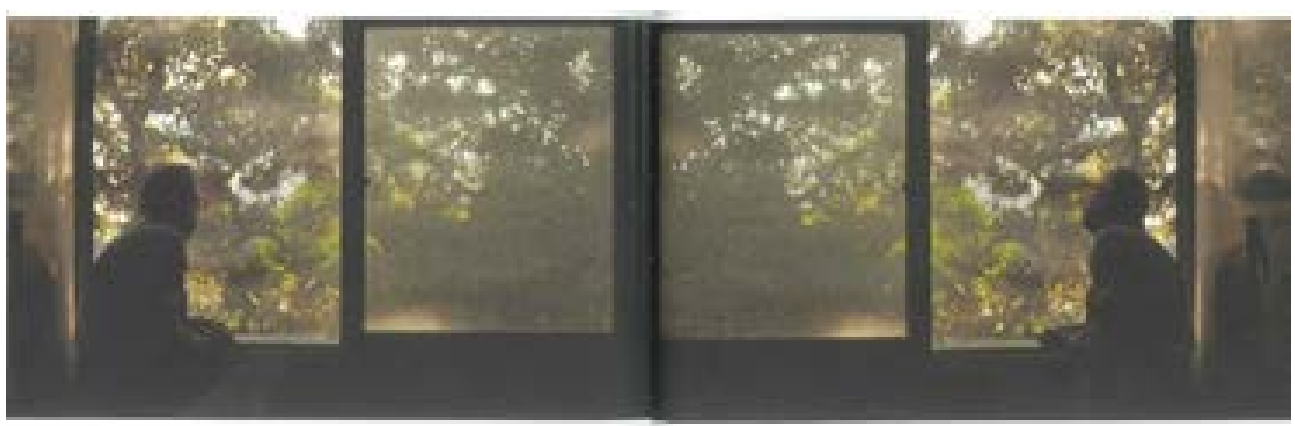

Fonte: DI NIGLIO, 2018

Devido à janela, às folhas e aos galhos das árvores e parte dos objetos que estão dentro da casa, é notório que o cenário é o mesmo em ambas as fotos, inclusive é a mesma pessoa, comprovado pela fisionomia da pessoa, os óculos e a roupa, que, mesmo escura, conseguimos visualizar os mesmos detalhes e as mesmas tonalidades na blusa ou camisa. Aliás, as duas fotos estão no mesmo plano de expressão - um plano americano com relação à pessoa, haja vista que em ambas ela aparece aproximadamente da cintura para cima. No entanto, não são nem as cores da roupa nem o cenário para fora da janela ou a disposição e abrangência da foto que mais despertam nossa atenção.

Resguardamos, portanto, nossos olhares à pessoa que está em frente à janela, em ambas olhando para fora, que é justamente o que mais nos sensibilizou. $\mathrm{Na}$ primeira foto, ela está olhando para baixo, como se estivesse triste, pensativa, ou esperando alguém chegar ou voltar para casa. Já na segunda, ela está olhando para cima, como se estivesse fazendo uma súplica, olhando aos céus e clamando por ajuda. Como presumimos que ela não está em perigo, seu pedido de ajuda seria para outra pessoa, da qual ela aguarda a chegada ou o retorno.

Em vista às leituras feitas das fotografias selecionadas, ratificamos que em muitas fotografias há a representação das vítimas da ditadura, não apenas aquelas que desapareceram, foram torturadas e mortas, mas também daqueles familiares que sofreram com a perda. Muitos destes guardam em suas memórias o trauma, a solidão, a tristeza, o sofrimento e, por fim, o desejo de que todas essas atrocidades estejam presentes apenas nas fotografias rememoradoras do passado.

\section{Considerações finais}

A fotografia como forma de representação e rememoração da memória tem novas e específicas funções associadas às técnicas fotográficas. Graças a ela e a toda tecnicidade de Diego Di Niglio nas fotografias publicadas no livro P14311, pudemos realizar novas e diferentes formas de leituras possíveis a respeito da representatividade da ditadura. Enfocamos nas vítimas vivas, ou seja, os familiares e amigos de pessoas desaparecidas e mortas naquele período histórico sangrento em que os porões eram utilizados não apenas para guardar objetos velhos e pouco usados.

Com parte da teoria voltada para conceito de lugar de fala e considerações do discurso voltadas também para essa definição, concluímos que as fotografias de Di Niglio, assim como muitos outros registros existentes com esses mesmos fins, são lugares de fala encontrados por fotógrafos, escritores e demais rememoradores da ditadura. Além do mais, essas fotografias, textos e livros não são apenas o lugar de fala dos vivos, mas também dos mortos, dos desaparecidos. Essas formas de registro tornam-se elementos de comunicação e propagação das vozes suprimidas, apagadas, aniquiladas, mas que não podem ser esquecidas. Esses lugares de fala nos reportam aos "discursos feitos de signos" de Foucault (2008, p. 55), dos quais também nos apropriamos na explanação teórica.

Ademais, a fotografia torna-se uma forma de testemunho e de criação, uma representatividade do real intencionada pelo fotógrafo, no caso dos registros de Di Niglio. Assim, somos convidados a revisitar os três estágios de Kossoy (2001): a intenção, que nas fotografias analisadas são inúmeras, sobretudo de representatividade do passado da ditadura; o(s) ato(s) de registro, no(s) qual(is) se utilizou várias técnicas e diferentes momentos; e à materialização da fotografia, que resultou em um belíssimo livro repleto de fotografias surpreendentes e, no final, somos presenteados com uma excelente elucidação textual do professor José Afonso Jr. 
Lembremo-nos, diante disso, das palavras de Deleuze (1999, p. 6) com relação ao fotógrafo: "se ele sabe captar admiravelmente as mãos em imagens é porque ele precisa delas. Um criador não é um ser que trabalha pelo prazer. Um criador só faz aquilo de que tem absoluta necessidade". Sendo assim, essas asseverações também podem ser relacionadas a Di Niglio, pois ele vê a necessidade de representar episódios da ditadura em suas fotografias.

Enfim, Di Niglio mostra a sua criatividade em todas as fotos, com diferentes ângulos, focos, enquadramentos e, sobretudo, apreensão da temática na fotografia. Mas não podemos nos esquecer de um dos principais objetivos - a rememoração da ditadura realizada e representada nas fotografias. Não nos esqueçamos da flor que simboliza a luta pela pacificação e também o luto dos familiares dos mortos. Tenhamos respeito e compaixão pelos idosos solitários, tristes, amargurados, traumatizados com o sofrimento embebido em traumas, memórias e lembranças, revividos e enlutados na arte, na literatura e na fotografia.

\section{Referências}

AMARAL, Márcia Franz. Lugares de fala: um conceito para abordar o segmento popular da grande imprensa. Revista Contracampo, Niterói, n. 12. p. 103-113, 2005. Disponível em: http:// periodicos.uff.br/contracampo/article/view/17388/11025. Acesso em: 22 jan. 2019. https:// doi.org/10.22409/contracampo.voi12.561

BARTHES, Roland. A câmara clara: nota sobre a fotografia. Tradução de Júlio Castañon Guimarães. Rio de Janeiro: Nova Fronteira, 1984. Disponível em: https://monoskop.org/ images/d/d3/Barthes_Roland_A_camara_clara_Nota_sobre_a_fotografia.pdf. Acesso em: 20 jan. 2019.

DELEUZE, Gilles. $O$ ato de criação. Tradução de José Marcos Macedo. São Paulo: Folha de São Paulo, 1999. Disponível em: https://lapea.furg.br/images/stories/Oficina_de_video/o\%20 ato\%20de\%20criao\%20-\%20gilles\%20deleuze.pdf. Acesso em: 21 jan. 2019.

DI NIGLIO, Diego. P14311. Pernambuco: Fundarpe, 2018

DUBOIS, Philippe. O ato fotográfico e outros ensaios. Tradução de Marina Appenzeller. Campinas, SP: Papirus, 1993. Disponível em: https://cteme.files.wordpress.com/2011/03/dubois-philippeo-ato-fotogrc3a1fico-e-outros-ensaios-2.pdf. Acesso em: 20 jan. 2019.
FELIZARDO, Adair; SAMAIN, Etienne. A fotografia como objeto e recurso de memória. Revista Discursos fotográficos. Londrina, PR: v.3, p.205-220, 2007. Disponível em: http://www.uel.br/ revistas/uel/index.php/discursosfotograficos/article/view/1500/1246. Acesso em: 20 jan. 2019. https://doi.org/10.5433/1984-7939.2007v3n3p205

FOUCAULT, Michel. A arqueologia do saber. Tradução de Luiz Felipe Baeta Neves. 7. ed. Rio de Janeiro: Forense Universitária, 2008. Disponível em: http://www.uesb.br/eventos/ pensarcomveyne/arquivos/FOUCAULT.pdf. Acesso em: 21 jan. 2019.

KOSSOY, Boris. Fotografia e história. 2. ed. rev. São Paulo: Ateliê Editorial, 2001. Disponível em: http://paginapessoal.utfpr.edu.br/bertucci/mestrado-estudos-de-linguagens/ppgelprocessos-de-producao-de-sentidos-em-diferentes-linguagens/aula-9-processos-de-producaode-sentidos-imagens-aula-2/KOSSOY-\%20B.\%20Historia\%20e\%20fotografia\%20-\%20cap.\%20 Fotografia\%20e\%20historia.pdf/at_download/file. Acesso em: 20 jan. 2019.

RIBEIRO, Djamila. O que é lugar de fala. Belo Horizonte: Letramento, 2017. p. 55-90. Disponível em: https://pt.scribd.com/document/374967246/0-Que-e-Lugar-de-Fala-Djamila-Ribeiro. Acesso em: 19 out. 2018. 